\title{
Design and Applications of the Circuit of Keyboard Display in Detecting Axle's Temperature System
}

\author{
Guilin $\mathrm{Lu}$ \\ Guangxi University of Technology, Liuzhou 545006, China \\ E-mail:lifishspirit@126.com
}

\begin{abstract}
The technology of detecting axle's temperature with infrared rays is a new kind of scientific product which plays an important part in the indemnity system of railway rolling stock, The circuit of keyboard and display is a man-machine interactive technology,which is composed of Chip 8279,LED digital display and correlative instruments.Coordinated by Chip 8279,LED digital display perform to read keyboard numerical values and display memory address ; power self-check is accomplished by the Voltage compare device in the circuit;the calendar clock chip 5832 makes the clock display possible. Experimental results accomplished with parameter show that the design of hardware and software is applicable to Infrared Rays System
\end{abstract}

Keywords: Hot axle, Detecting axle's temperature, The circuit of keyboard display, Man-machine interactive

\section{Preface}

The detecting axle's temperature with infrared rays systemy Can find hot axle of wheel in time, so it becomes an important equipment in preventing wheel from being disconnected., and it is a new kind of scientific product which plays an important part in the indemnity system of railway rolling stock.it can detect wheel's hot axle effectively and indemnify rolling stock against danger through making use of the theory of detecting temperature with infrared rays.

The detecting axle's temperature with infrared rays system of the Second generation has concentrated computer, optical and automatic control.it can trail inspecting running train continuously, find all kinds of hot axle faults of rolling stock automatically, alarm managers with speech.it consists of surveying station, showing station, inspecting center and Inquity Terminal.surveying station is one of major composition parts of the rolling stock's axle temperature inspection equipment.

Surveying station includes: circuit of keyboard display, wheel sensor board, the input board of axle temperature, export control plate, serial interface board and transmitting data board. GAL20V8 chips used to describe features, According to the small keyboard provided by the memory, storage registers to analyze the data to judge the work of Surveying stations, The network self-test system to form a central message and communications, the central management system carry out network management about surveying stations and showing stations, trail hot axle of passing train, forecast according to three grades: low hot, strong hot and surge hot.

\section{Design of Keyboard display circuit}

The system hardware was design by Module, Including the CPU module, memory modules, graphics display module, A / D module, D / A module, the volume switch I / O modules, All was made by the standard size plug-in manufacturing. The functional module can be inserted any socket, In most cases, only to be replaced circuit template, they can change the function of the system, System module with the bus and the function that describes the figure 1:

The modular system was denoted with code JC, JC17 case of the module's functions GAL20V8 chip is described as follows:

MODULE ENCODER1

FLAG '-R3';

TITLE ENCODER;

ENCODER DEVICE 'P20V8S';

K2, CPU_DEN, HLDA PIN 1,2,4,8; 


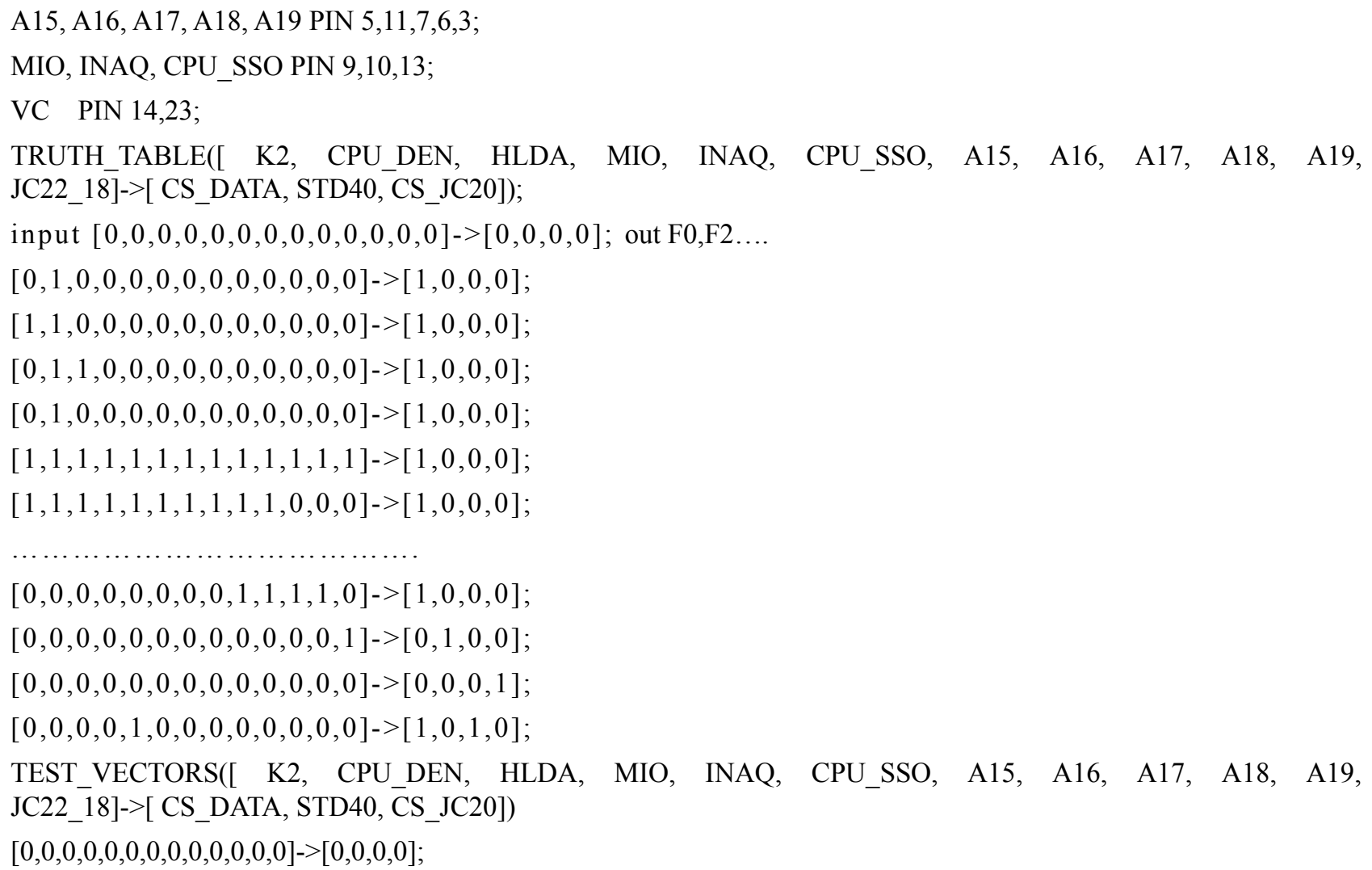

\section{END ENCODER1}

\section{Circuit of keyboard display}

This is described in the next ABEL3.0.Its keyboard display circuit chip hardware includes two 8279 and 74LS138, hardware design to solve two questions:

(1)The key to the elimination of jitter. Delay by the general procedures (such as delay 20ms) button on the Elimination of jitter.

(2) Should be prevented by a key and a number of key input

We use software to scan lines using methods and procedures to achieve law.

Which shows that the digital keyboard design sub-flow chart, Shown in Figure 2.

Figure 3 of Subroutine of deal with keyboard design flow:

Keyboard display circuit function, as shown in Figure 4.

\section{Simulation tests}

In the PCB has a good system, we choose the keyboard show circuit module in the voltage comparator, In its anti-interference measures for the R8's choice, Various components of the value of the pressure point of view:, $\mathrm{U}_{B}>2.5 \mathrm{~V}$, Found to point B-to-ground resistance $\mathrm{R}_{13}=145 \Omega$, Therefore, to point $\mathrm{B}$ to measure output voltage $\mathrm{UB}$, As shown in Figure 5

Choose $\mathrm{C}_{2}=1 \mu \mathrm{F}, \mathrm{R}_{15}=150 \mathrm{k} \Omega$, Detected UB $>2.5 \mathrm{~V}$. It is correct value that Note capacitor $\mathrm{C} 2$ and resistance the of $\mathrm{R} 15$. to choose

PROTEL through the simulation test, Check out point B voltage, As shown in Figure 6.

Soluting:

jC11 pick in the R1 resistance $10 \mathrm{k} \Omega$, R8 resistance from $1 \mathrm{k} \Omega$ to $10 \mathrm{k} \Omega$ compared to arrive at the most appropriate resistance., To observe the Out4, Out2, Out1, Out3, int1, int2, int3 wave, The results shown in Figure 7.

The experimental results: $\mathrm{R} 8=10 \mathrm{k} \Omega$, Requirements for fit.

\section{The keyboard show circuit module of the completion of the main functions}

The design of the above, the completion of the functions of monitoring power status: This keyboard display board to monitor $+5 \mathrm{~V},+12 \mathrm{~V},-12 \mathrm{~V}$ supply voltage changes, Power supply will be sent to the state's population 00CH-D0 ---- D5, 
00CH state voltage and the D0 --- D5-relationship shown in Table 2.

\section{Summary}

Infrared detection systems show circuit keyboard software, hardware can be effectively completed the task of man-machine dialogue, Including the completion of the design and performance are: Reading of the key, the corresponding keys on the car have been reported, Self-examination revealed, Display and memory addresses, Signal is collected by Based on 8086 Microprocessor,

Users of the implementation process, the exchange of information between the device and improve the original infrared temperature detection system in response to slow real-time requirements of the inadequacies of the poor.

\section{References}

Chen Gang, Zhang Yun. (1976). Second-generation infrared temperature detection system,1997, 6.

Luguilin. (2002). China University of Science and Technology Master's Degree Essays.

Wang, Ying. (1995). Temperature monitoring of railway network communications records "black box", Electrical measuring and instruments, 1995, 5.

Table 1. 00CH state voltage and the D0 --- D5-relationship

\begin{tabular}{|c|c|c|}
\hline \multicolumn{2}{|c|}{ Data state } & Meaning \\
\hline $\mathrm{D} 0=1$ & $\mathrm{D} 3=1$ & That is normal in Duty $5 \mathrm{~V}$ voltage between $4.5 \mathrm{~V}$ to $5.5 \mathrm{~V}$ \\
\hline $\mathrm{D} 0=0$ & $\mathrm{D} 3=1$ & voltage $5.75 \mathrm{~V}$ said that more than exceeded the upper limit $5 \mathrm{~V}$ \\
\hline $\mathrm{D} 0=1$ & $\mathrm{D} 3=0$ & Voltage that is less than $4.25 \mathrm{~V}$, below the lower limit of $5 \mathrm{~V}$ \\
\hline $\mathrm{D} 1=1$ & $\mathrm{D} 4=1$ & That the value of the voltage is between $10.2 \mathrm{~V}$ to $13.8 \mathrm{~V}$, normal \\
\hline $\mathrm{D} 1=0$ & $\mathrm{D} 4=1$ & It Said over-voltage $13.8 \mathrm{~V}$, in excess of the maximum $12 \mathrm{~V}$ \\
\hline $\mathrm{D} 1=1$ & $\mathrm{D} 4=0$ & Less than that voltage $10.2 \mathrm{~V}$, below the lower limit of $12 \mathrm{~V}$ \\
\hline $\mathrm{D} 2=1$ & $\mathrm{D} 5=1$ & $-12 \mathrm{~V}$ voltage, said in- $13.8 \mathrm{~V}$ to- $10.2 \mathrm{~V}$, normal \\
\hline $\mathrm{D} 2=0$ & $\mathrm{D} 5=1$ & More than that voltage- $13.8 \mathrm{~V}$, in excess of the maximum- $12 \mathrm{~V}$ \\
\hline $\mathrm{D} 2=1$ & $\mathrm{D} 5=0$ & $\begin{array}{l}\text { Voltage that is less than the above- } 10.2 \mathrm{~V} \text {, which is lower than the } \\
\text { minimum- } 12 \mathrm{~V}\end{array}$ \\
\hline
\end{tabular}




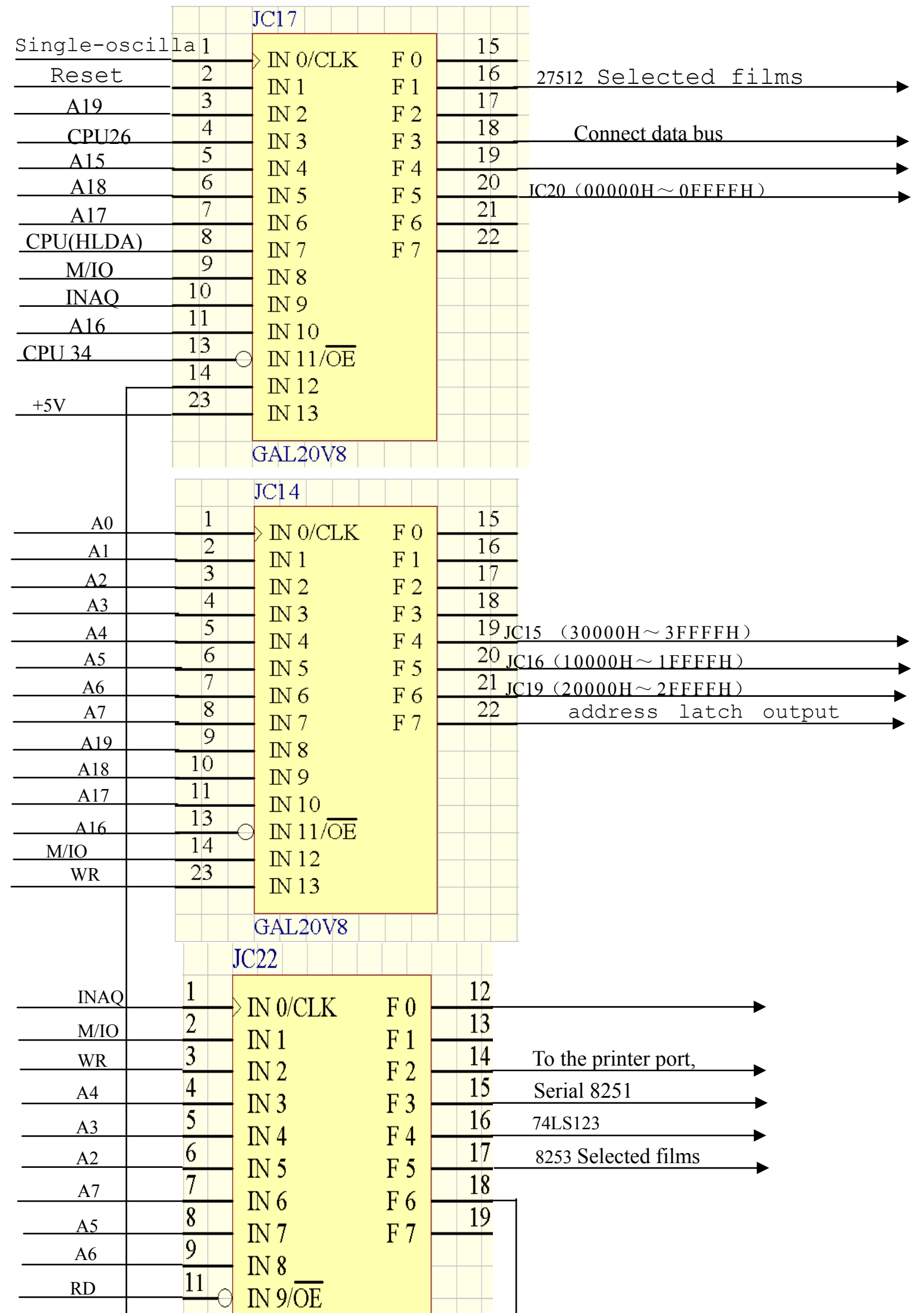

Figure 1. 


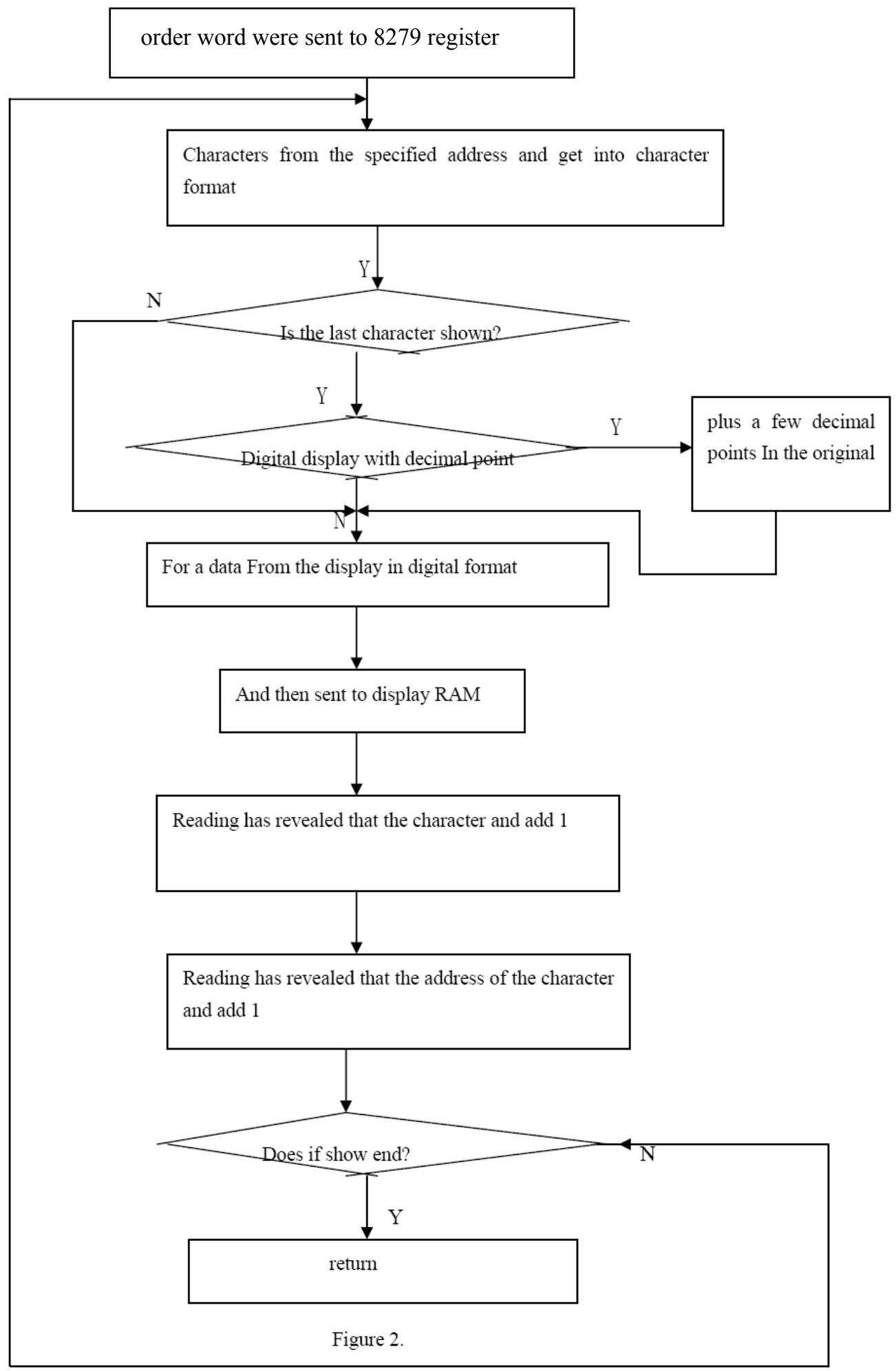




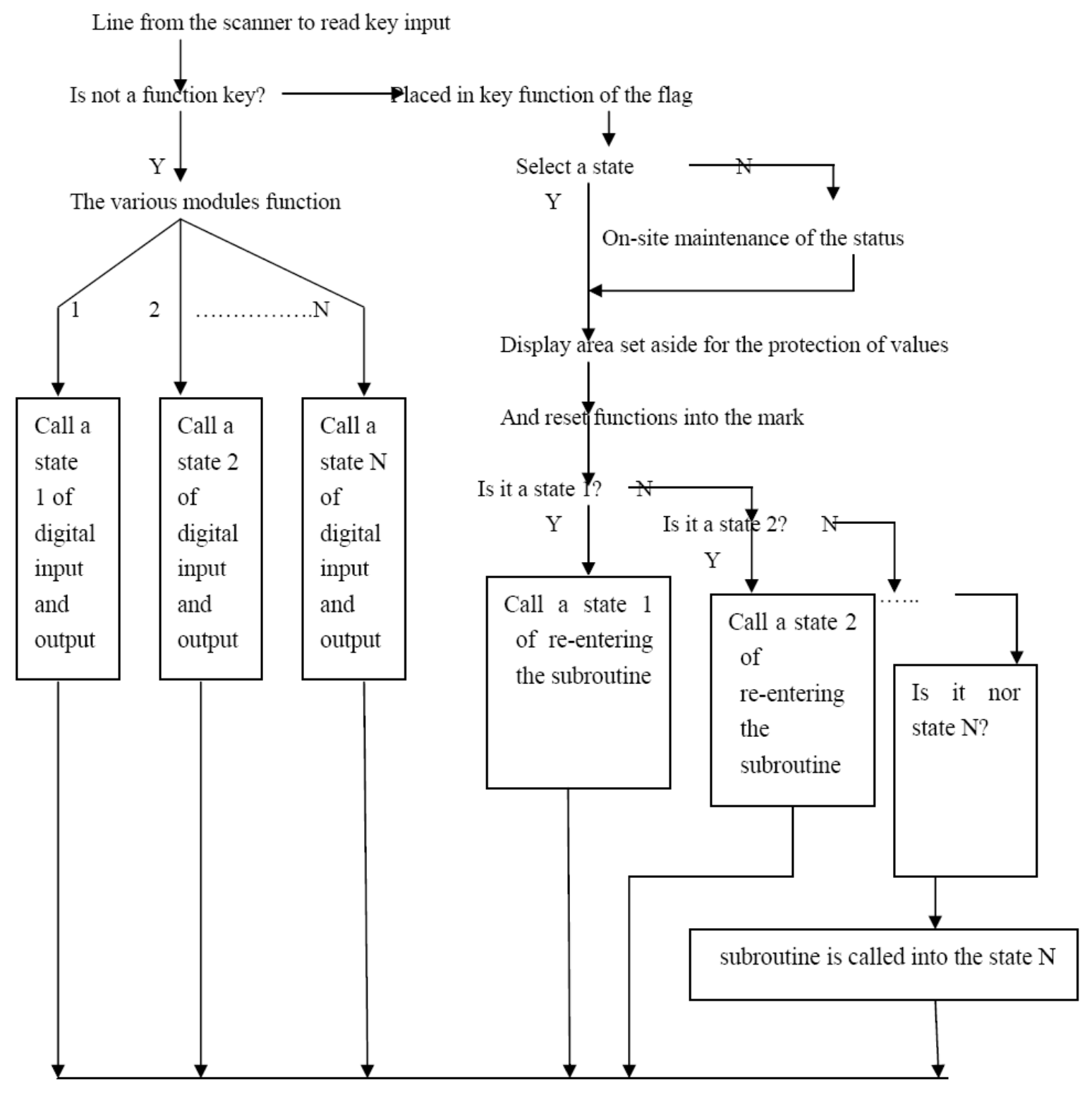

Figure 3. 


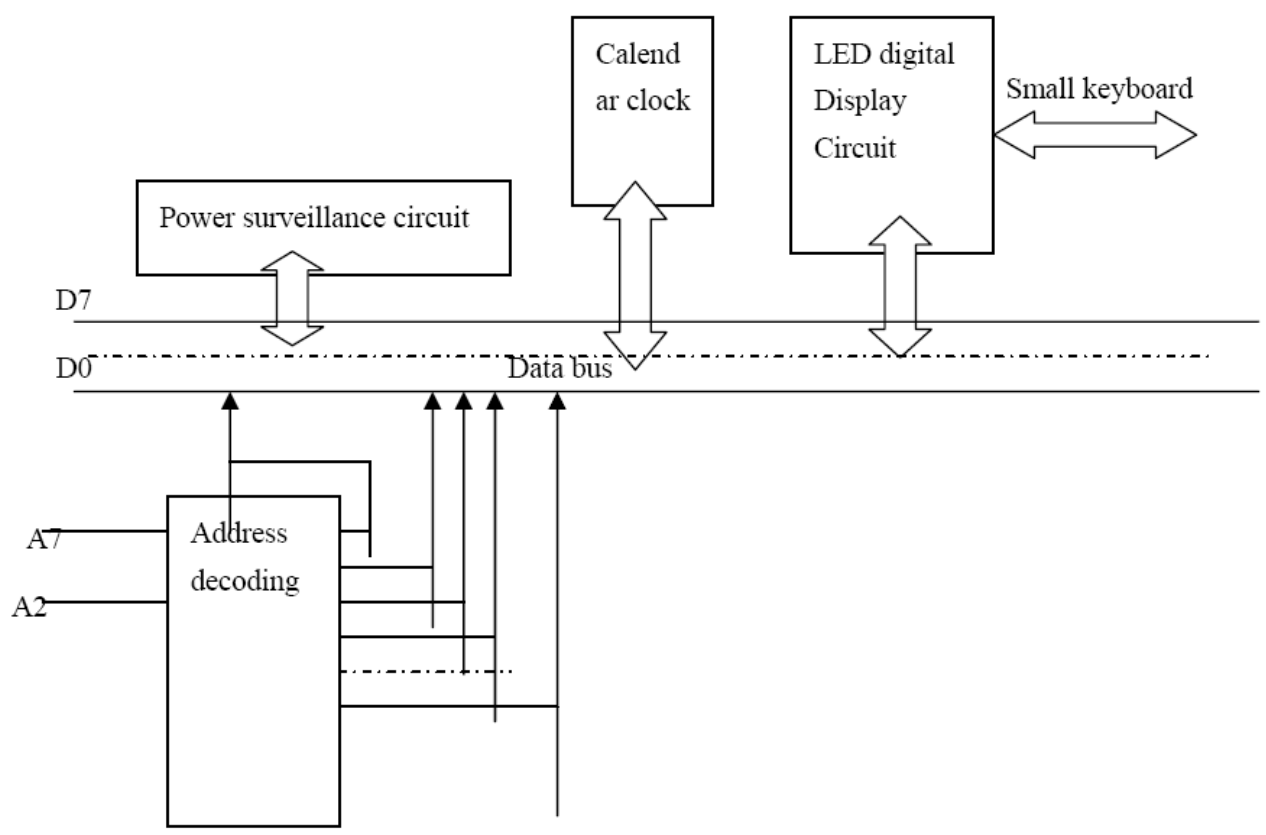

Figure 4.

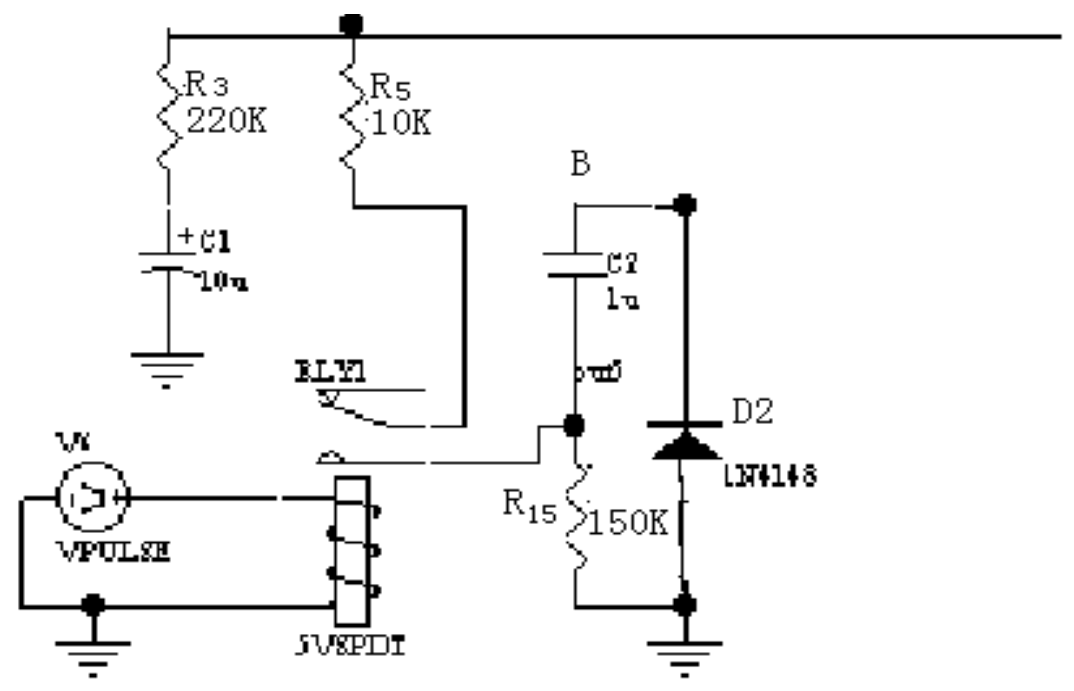

Figure 5. Point B test voltage map 


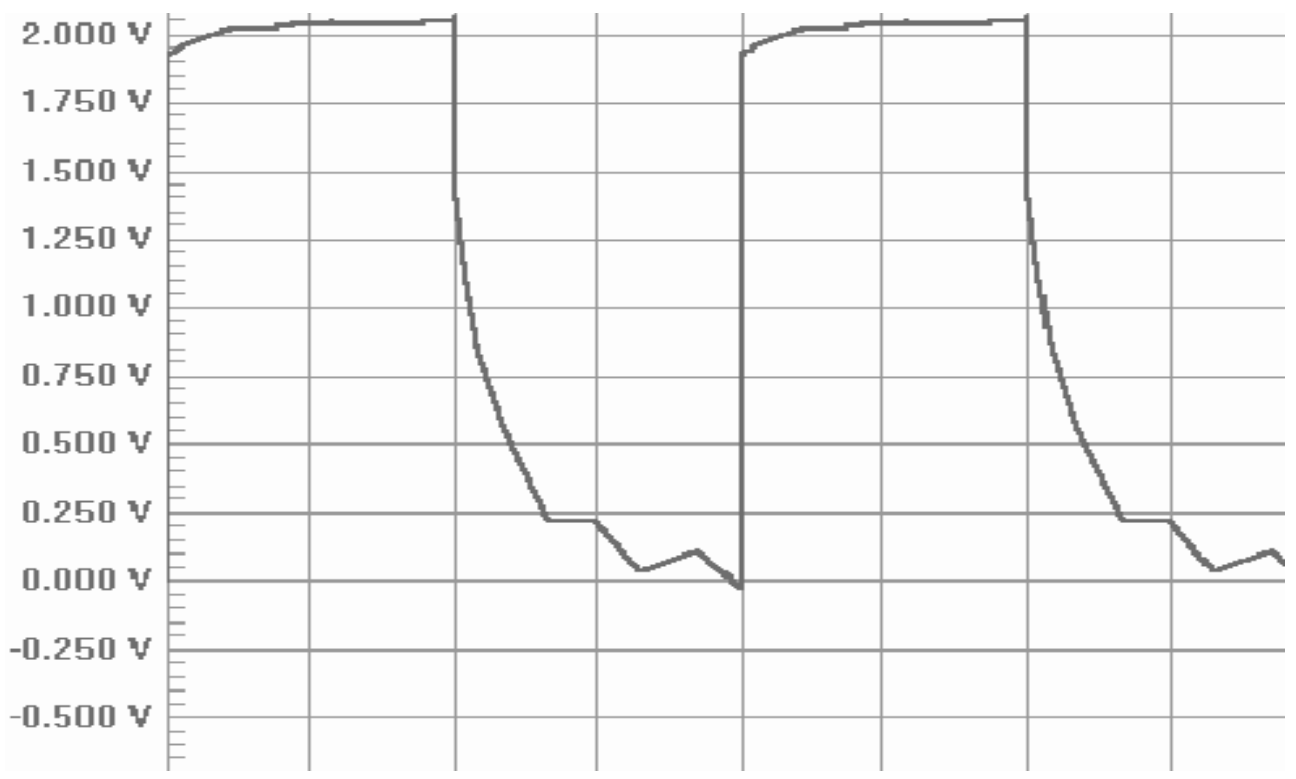

Figure 6. B-point voltage value map

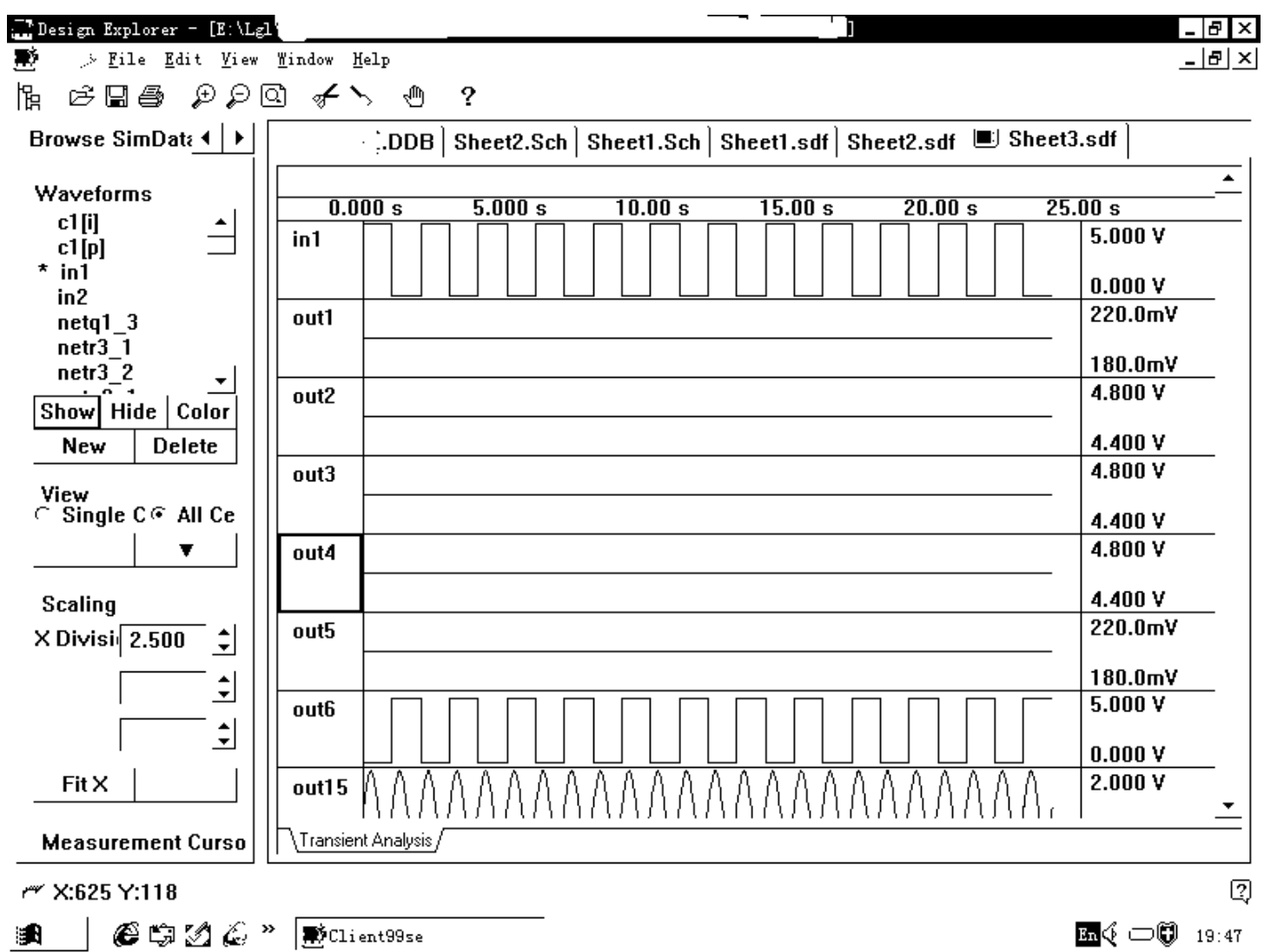

Figure 7. The results map 